\title{
ANTI-SEISMIC DEVICE DESIGN FOR CONTAINER CRANE AND ITS ELASTIC-PLASTIC TIME HISTORY ANALYSIS
}

\author{
Dashan Dong, \\ Jin Li, \\ Yuanyuan Teng, \\ School of Logistical Engineering, Shanghai Maritime University, Shanghai
}

\begin{abstract}
Quayside container crane is a kind of large dimension steel structure, which is the major equipment used for lifting container at modern ports. With the aim to ensure the safety and reliability of the crane under seismic loads, an anti-seismic device is designed. To validate the efficiency and reliability of the anti-seismic device, elastic-plastic time history analysis under rare seismic intensity is carried out. And the results of elastic-plastic time history analysis when the crane installed anti-seismic device and uninstalled the device are compared.
\end{abstract}

Keywords: quayside container crane, time history analysis, energy design method, anti-seismic device

\section{INTRODUCTION}

Quayside container crane is the main equipment used for lifting containers at modern harbors. However, most major ports are built in the seismic belts. In order to avoid damage to the crane under the earthquake, a frictional anti-seismic device is designed for the container crane.[4-5]

In this paper, an anti-seismic device is designed for the quayside container crane, and the efficiency of the device is validated by the time-history analysis and model simulation. In order to ensure the accuracy of the analysis, the seismic waves are provided by the local Seismological Bureau in Los Angeles, where is also the J481 crane located.

\section{COMMON ANTI-SEISMIC MEASURES FOR QUAYSIDE CONTAINER CRANES}

Anti-seismic design is widely used in high buildings and important buildings. There are lots of anti-seismic methods, such as the TMD, TLD or use the seismic isolation devices to reduce the damage to the structure. Because of the complexity of the container crane, it's hard to use a TMD or TLD device on the structure. According to the crane's characteristics, some commonly used anti-seismic design methods are the following:

1) Elastic leg-lift design to lift the legs under the earthquake. Leg-lift has eliminated the constraints between the crane and the ground, thus prevented the transfer and increase of the lateral loads, and limited the transfer of the acceleration of earthquake.

2) Plastic frame design to adapt to the deformation that occurred during the earthquake. If the deformations of legs are beyond the capacity, crane collapse occurs.
3) Seismic isolation device design. Fig.1 shows a seismic isolation device use the dampers and springs as isolation components. Besides, seismic isolation devices can also use the friction pairs as isolation and energy components.

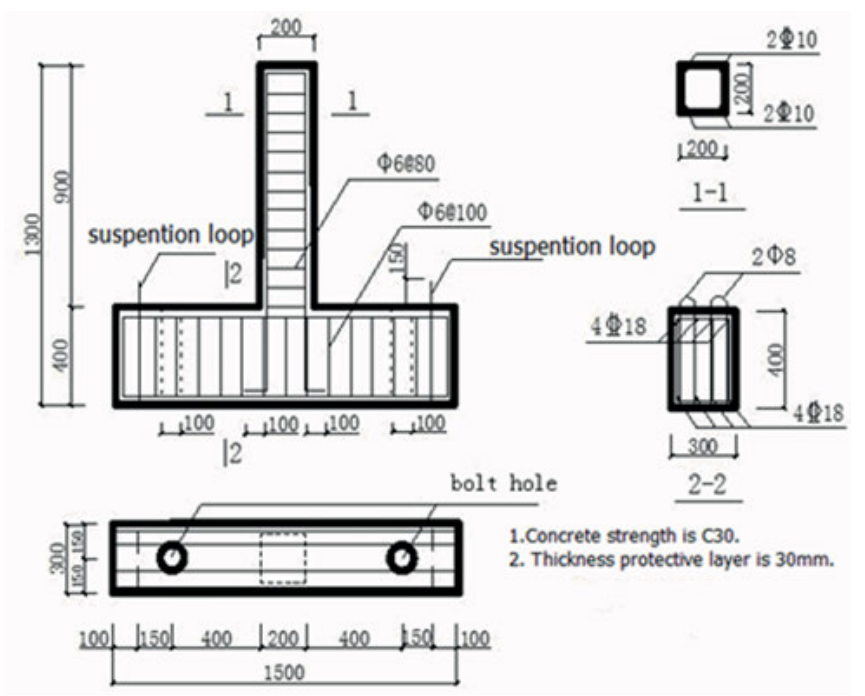

Fig. 1. Seismic isolation device's Schematic diagram

\section{ANTI-SEISMIC DEVICE DESIGN WORKING PRINCIPLES}

In this paper the frictional anti-seismic device uses several slotted bolted connections as the main structure, which is referred to as SBCs. Fig.2 shows the slotted bolted connection. 
Compared with other types of anti-seismic device, SBCs has the following advantages:

1) It not only can be used for general bracing in single frame structure but also to connect the beam-column joints. And it just needs to make minor changes to the original standard structure without affecting the original design functions.

2) SBCs are easy to construct, and the materials are not special. It has obvious economic benefits.

3) SBCs can maintain a stable and high efficiency energy consumption under multiple cycles.

4) Before slipping the anti-seismic device works as a general support to increase the lateral stiffness and reduce the structural deformation. When slipping the structural stiffness has changed, while the stress is always kept in a controlled elastic stage[2].

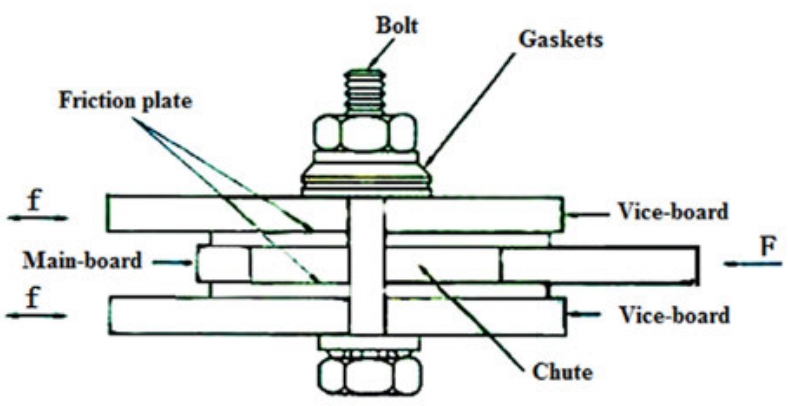

Fig. 2. The slotted bolted connection

\section{ENERGY METHOD}

\section{ENERGY DEMAND OF ANTI-SEISMIC DEVICE}

For the structure without the anti-seismic device, part of the seismic energy input to the structure stored in the form of elastic deformation energy and kinetic energy. Another part of energy is consumed by non-elastic deformation generated by the structure itself (Formula 1).

For the structure with the anti-seismic device, not only have the same energy consumption form as general structure, but also the additional energy consumption device will absorb and consume most of the seismic input energy (Formula 2).

If the structure is not destroyed in the earthquake, the energy consumption and seismic input energy should keep a balance.

For the structure without the anti-seismic device:

$$
E_{I}=E_{K}+E_{D}+E_{L}+E_{H}
$$

For the structure with the anti-seismic device:

$$
E_{I}^{\prime}=E_{K}^{\prime}+E_{D}^{\prime}+E_{L}^{\prime}+E_{H}^{\prime}+E_{M}
$$

\section{ENERGY DISSIPATION CAPABILITY}

The energy dissipation capacity is closely related with the displacement of the frictional anti-seismic device.[3] It can be calculated by hysteresis curves and its approximate expression is:

$$
E_{M}=n \varphi m E_{M i} \cos \theta
$$

The recovery force model of anti-seismic device can be seen as the ideal rigid-plastic model. So the energy consumed by one anti-seismic device in one cycle is:

$$
E_{M i}=4 F_{y} d_{0} \cos \theta
$$

\section{CHUTE DISTANCE SETTING}

The chute distance setting is one of the most important steps about frictional anti-seismic device's design. If the chute design distance is too long, it will affect the structure stiffness even lead to structural damage. While if the chute distance is too short, the anti-seismic device needs a larger one-way trip to dissipate the energy. That will collide with the chute ends and make additional dynamic impact to the structure.
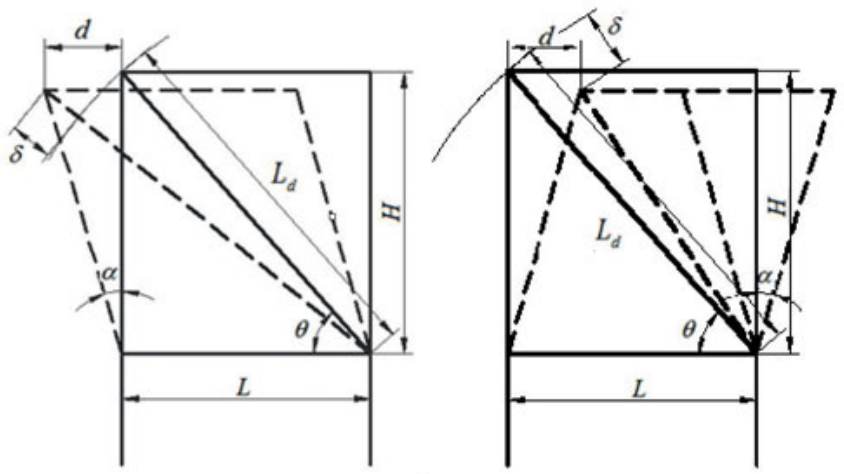

Fig. 3. Deformation of Structural with anti-seismic device

Tab. 1. The relationship of the structural damage and the displacement angle between layers

\begin{tabular}{|c|c|c|c|c}
\hline Basic good & Minor damage & Moderate damage & Severe damage & Collapse \\
\hline $1 / 500$ & $1 / 500 \sim 1 / 250$ & $1 / 250 \sim 1 / 125$ & $1 / 125 \sim 1 / 50$ & $1 / 50$ \\
\hline
\end{tabular}

\begin{tabular}{l|l|l|l|l|}
\hline $1 / 500$ & $1 / 500 \sim 1 / 250$ & $1 / 250 \sim 1 / 125$ & $1 / 125 \sim 1 / 50$ & $1 / 50$ \\
\hline
\end{tabular}

To ensure the structure does not collapse that (Tab.1):

$$
\tan \alpha=\frac{d}{H} \leq \tan \left(\frac{1}{50}\right)
$$

Where, $\alpha$ is the displacement angle between layers.

From Fig. 3 we can get, when the frictional anti-seismic device in a stretched state the maximum offset is:

$$
\delta_{\max }=\sqrt{H^{2}+(L+0.02 H)^{2}}-L_{d}
$$

When the frictional anti-seismic device in a compressed state the maximum offset is:

$$
\delta_{\max }=L_{d}-\sqrt{H^{2}+(L-0.02 H)^{2}}
$$

So the design chute distance can't exceed the minimum offset value either when the frictional anti-seismic device is in a stretched or compressed state. According to dimensions of the crane specifically designed for Port of Los Angeles, the chute length is .

\section{SLIDING FORCE CALCULATION}

J481 quayside container crane is designed for Port of Los Angeles of the United States. According to tender requirements, 
various structure calculations under different loads and situation has done with ANSYS. Results show that the largest load in diagonal brace is 202 ton.

When apply $0.3 \mathrm{~g}$ earthquake vibration amplitude in the direction of trolley runs, the largest load in diagonal brace is 259 ton. Since the condition considered is the toughest, the actual force is generally less than the calculated force. Therefore, we set the sliding force of the anti-seismic device is 212 ton. So when the local vibration amplitude comes to $0.3 \mathrm{~g}$, the anti-seismic device working.

According to the design methods above, the anti-seismic device is shown in Fig.4.

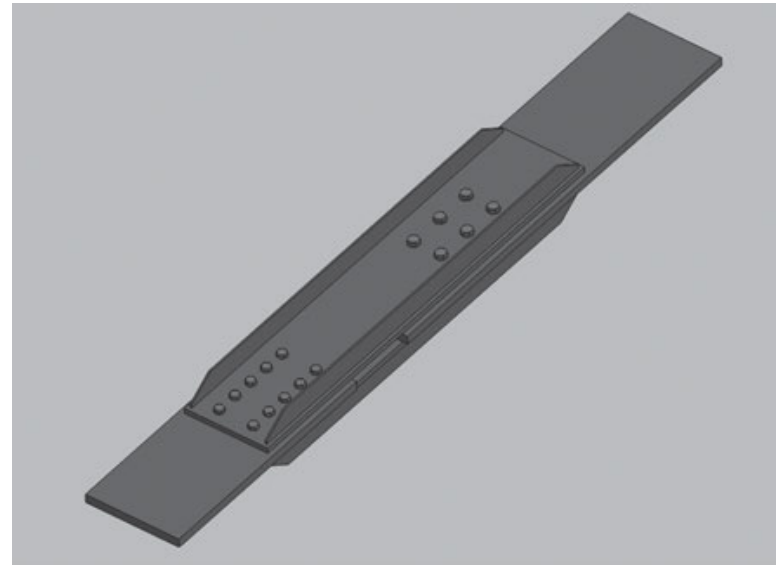

Fig. 4. One piece of anti-seismic device

\section{INSTALLATION LOCATIONS}

According to the basic design principles, experience and the purposes that SBCs only can be applied to the single bracing support or beam bottom support, we can determine the layout locations of the frictional anti-seismic devices. Fig. 5 shows the examples of anti-seismic devices' installation on single bracing support container crane.

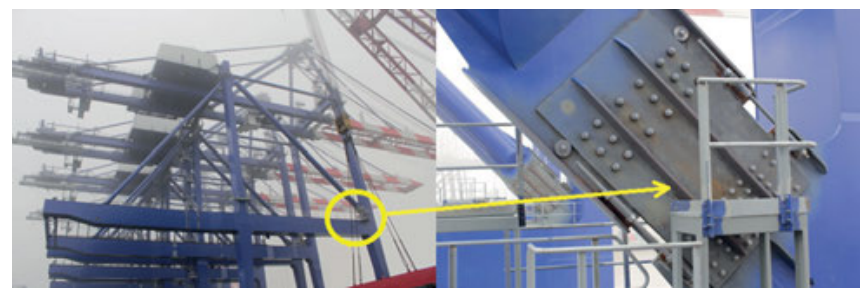

Fig. 5. Examples of anti-seismic devices' installation on single bracing support container crane

\section{SELECTION OF THE SEISMIC WAVE}

In this paper, a time-history analysis of J481 quayside container crane is presented respectively under the occasional level seismic wave (CLE).

Since the provided seismic waves recorded a long time, most of the time it makes a tiny vibration on the structure. It is very necessary to intercept some parts of the seismic waves to analysis. We intercept the acceleration which is bigger than $0.1 \mathrm{~g}$ of the CLE seismic wave. Input the selected seismic wave data to do the time-history calculation based on the ANSYS.
Belong to the analysis results by the seven CLE waves, the 2 th and 4th make the greatest impact on the structure, which is named as CLE-2 and CLE-4. In the following presentation we take CLE-4 (FP direction) as an example. The time-history curves as shown in Fig. 6.

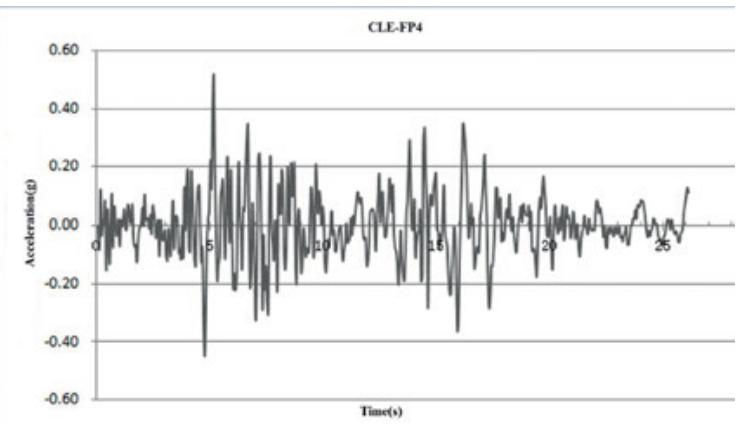

Fig. 6. Time-history curves under CLE-4

\section{TRADITIONAL CRANE SYSTEM DYNAMIC TIME-HISTORY RESULT}

Apply the seismic loads on the J481 container crane, and then do the time-history analysis. [6] The results show the structure's response under vary seismic waves. The analysis results under CLE-4 seismic wave as shown in Fig.7 9.

Under the occasional level seismic waves (CLE-2 and CLE-4) crane's maximum stress over the entire time is larger than the structure's yield limit, and crane is in the elastic-plastic stage. The maximum displacement at the joint is bigger than the maximum allowable displacement. So the crane without anti-seismic device doesn't meet the anti-seismic requirements under occasional earthquake.

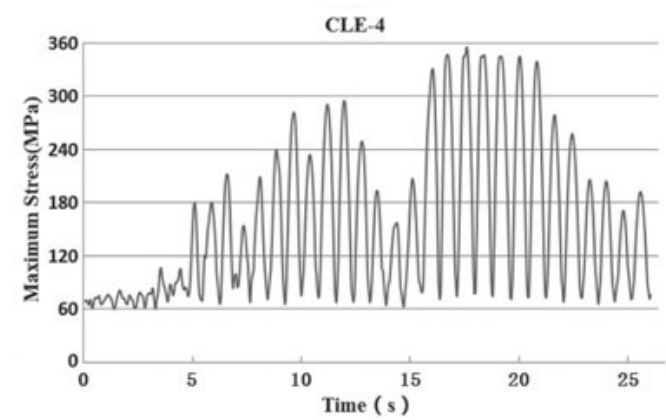

Fig. 7. The structure's maximum stress-time history curves under CLE-4 seismic wave without anti-seismic device

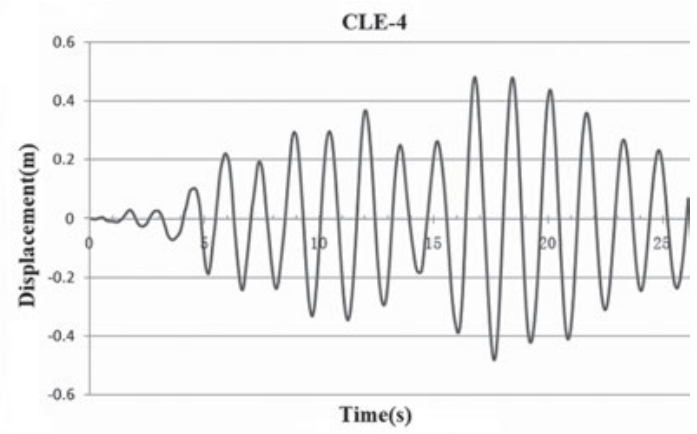

Fig. 8. The maximum displacement of the joint at the balance beam under CLE-4 without anti-seismic device 


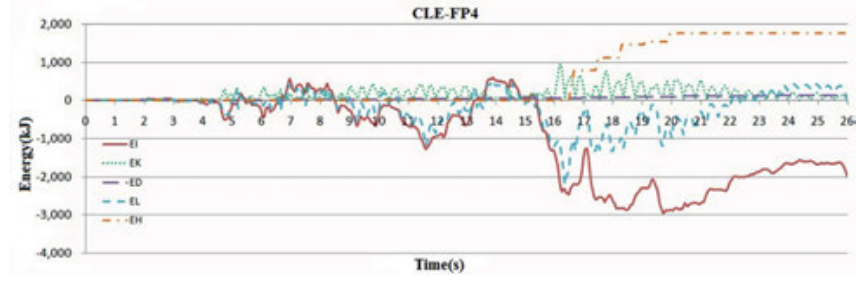

Fig. 9. The various energy sub-charts when the structure under CLE-4 seismic waves without anti-seismic device

\section{TIME-HISTORY ANALYSIS OF STRUCTURE WITH ANTI-SEISMIC DEVICE[7]}

Under the occasional level seismic waves (CLE-2 and CLE4), J481 container crane which is installed with the anti-seismic device is always in the elastic stage, and avoid the damage caused by plastic deformation. It can be seen that the device makes a great effect. Specific results can be found in Fig. 10 to 13. Take CLE-4 as an example.

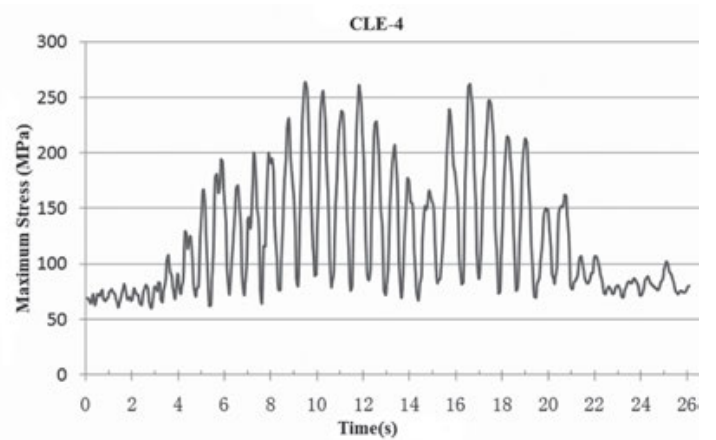

Fig. 10. Maximum stress-time history curves under the CLE-4 with antiseismic device

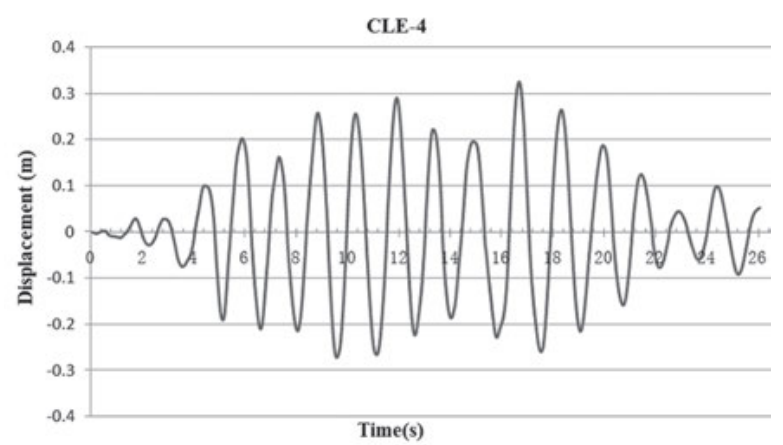

Fig. 11. The maximum displacement of the joint at the balance beam under CLE-4 with anti-seismic device

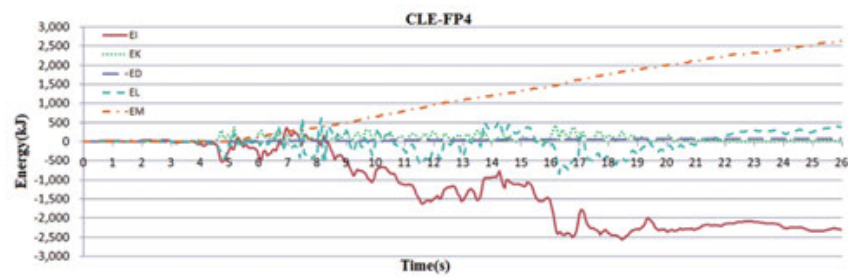

Fig. 12. Various energy sub-charts of structure with anti-seismic device under CLE-4 with anti-seismic device

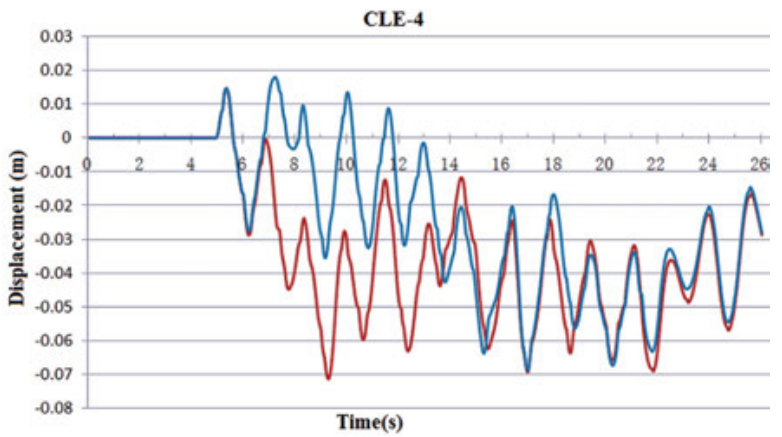

Fig. 13. Displacement-Time history curves of anti-seismic device under CLE-4

\section{DYNAMIC TIME-HISTORY ANALYSIS OF ANTI-SEISMIC DEVICE}

Under the occasional level seismic waves and considerate the thermal expansion of frictional damper[1], the transient simulation can provide the load-displacement-time history curves, hysteresis curve and energy consumption of the device, which is shown in Fig.14 to 16.[3]

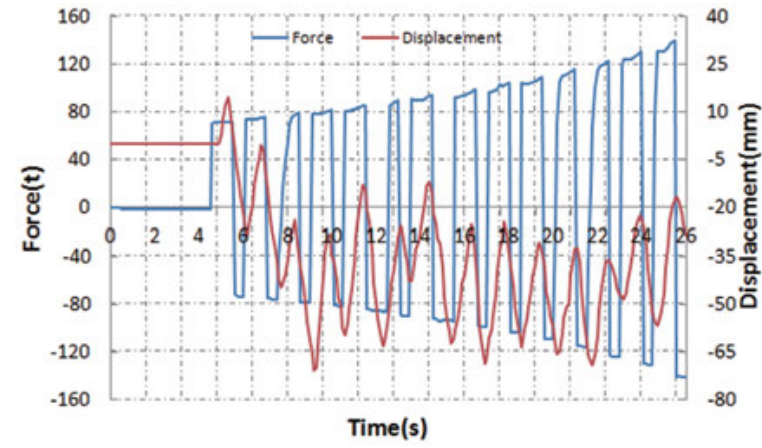

Fig. 14. The force-displacement-time history curves of anti-seismic device under CLE-4

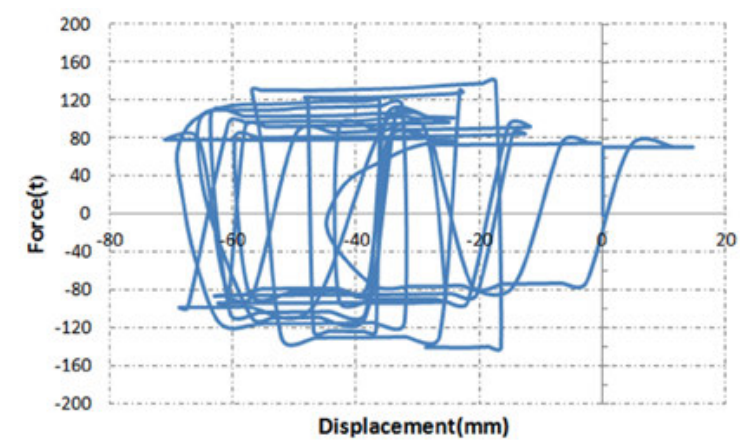

Fig. 15. Hysteresis curve of anti-seismic device under CLE-4

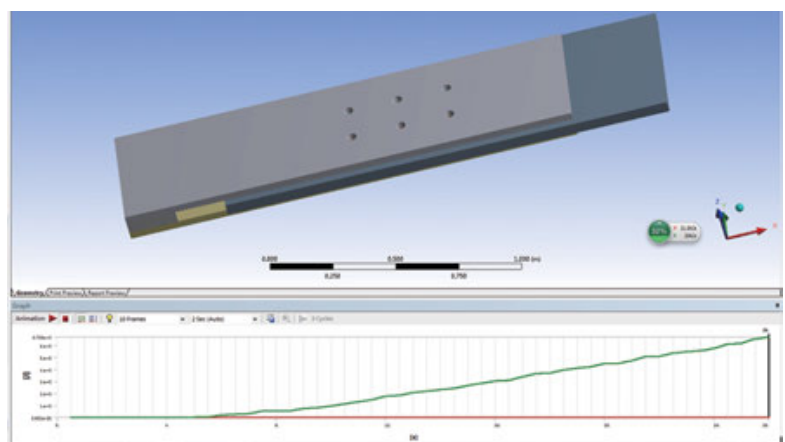

Fig. 16. Energy consumption of anti-seismic device under CLE-4 
Under the CLE-2 seismic wave, according to the simulate model's energy consumption and formula 3, the total energy consumption is $1163.76 \mathrm{~kJ}$. The energy consumption based on the energy sub-item time-history analysis is $1290 \mathrm{~kJ}$. The calculation error is within $9.78 \%$. Similarly, the calculation error is within $1 \%$ when under the CLE- 4 .

The analysis above proves that the anti-seismic device can effectively consume energy under the strong earthquakes.

\section{CONCLUSIONS}

In this article, we build the normal, anti-seismic device element model of crane and calculate the dynamic response acceleration by the time-history analysis. According to the research, we can get some conclusion as following:

1) The anti-seismic device based on SBCs can effectively consume energy under the strong earthquakes.

2) Energy method is suitable for quayside container crane's seismic response analysis. Its accuracy is verified by the energy calculated by the method of simulation and hysteresis curves of time-history analysis.

3) The impact to energy consumption caused by thermal expansion in the frictional anti-seismic device cannot be ignored.

\section{REFERENCE}

1. AA Yevtushenko, P Grzes, The FEM-modeling of the frictional heating phenomenon in the pad/disc tribo system, Numerical Heat Transfer, Part A, 2010

2. Grigorian C E and Popov E P, Slotted Bolted Connections for Energy Dissipation, Proc. of Senminar on Seismic Isolation, Passive Energy Dissipation and Active Control, Vol.2. San Francisco, USA, 1993

3. I Lopez, JM Busturia, H Nijmeijer,Energy dissipation of a friction damper, Journal of sound and vibration, 2004

4. KW Min, JY Seong, J Kim, Simple design procedure of a friction damper for reducing seismic responses of a single-story structure, Engineering Structures, 2010

5. Lee SK, Park JH, Moon BW, Min KW, Lee SH, Kim JK. Design of a bracing-friction damper system for seismic retrofitting. Smart Struct Syst 2008;4(5):685-96.

6. Zheng Pei, Zhang Qing, Qin Xian Rong. Earthquake Response Behavior of Quayside Container Cranes. Journal of Wu Han University of Technology. 2010. Vol.21.3.:70-74

7. Zheng Pei, Zhang Qing. Analysis of anti-seismic behavior of large-scale container cranes. Engineering Journal of Wu Han University. 2010. Vol.43. :116-12

\section{CONTACT WITH AUTHOR}

\author{
Dashan Dong \\ Jin Li \\ email: hellolijin1209@163.com \\ tel.: 86-15800307906 \\ Yuanyuan Teng \\ School of Logistical Engineering \\ Shanghai Maritime University \\ 201306 Shanghai
}

